\title{
Safety And Efficacy of ICls Plus Anlotinib Vs Anlotinib Alone As Third-Line Treatment In Extensive-Stage Small Cell Lung Cancer: A Retrospective Study
}

\section{Qing Chen}

Shandong Cancer Hospital: Shandong Cancer Hospital and Institute

\section{Yan Li}

Shandong Cancer Hospital and Institute, Shandong First Medical University and Shandong Academy of Medical Sciences

\section{Wenjie Zhang}

Shandong University Affiliated Shandong Tumor Hospital and Institute: Shandong Cancer Hospital and Institute

\section{Chen Wang}

Shandong Cancer Hospital: Shandong Cancer Hospital and Institute

\section{Shengjie Yang}

Shandong Cancer Hospital and Institute, Shandong First Medical University and Shandong Academy of Medical Sciences

\section{Qisen Guo ( guoqs369369@163.com )}

Shandong Cancer Hospital and Institute, Shandong First Medical University and Shandong Academy of Medical Sciences https://orcid.org/0000-0003-4304-6431

\section{Research Article}

Keywords: ES-SCLC, anlotinib, immune checkpoint inhibitors, safety, efficacy

Posted Date: August 11th, 2021

DOl: https://doi.org/10.21203/rs.3.rs-793454/v1

License: (1) This work is licensed under a Creative Commons Attribution 4.0 International License. Read Full License

Version of Record: A version of this preprint was published at Journal of Cancer Research and Clinical Oncology on November 19th, 2021. See the published version at https://doi.org/10.1007/s00432-021- 
03858-2.

Page 2/17 


\section{Abstract}

Purpose: The objective of this study was to evaluate safety and efficacy of Immune checkpoint inhibitors (ICls) plus anlotinib as third-line treatment in extensive-stage small cell lung cancer (ES-SCLC).

Methods: 120 patients with ES-SCLC admitted to Shandong Cancer Hospital between January 2019 and December 2020, were retrospectively analyzed. They were divided into observation group $(n=62)$ and control group $(n=58)$ according to different treatment plans. Observation group were given ICls plus anlotinib, while control group were given anlotinib alone. The primary endpoint of the study was progression free survival (PFS), and the secondary endpoints were objective response rate (ORR) and disease control rate (DCR). Efficacy evaluation was carried out every 2 cycles of the treatment. Univariate and multivariate analyses were performed to determine the prognostic factors. The main adverse events were evaluated according to the Common Terminology Criteria for Adverse Events version 5.0.

Results: In observation group and control group, the DCR were $87.1 \%$ and $72.4 \%(p=0.044)$, and the ORR were $19.4 \%$ and $6.9 \%(p=0.045)$, respectively. The median PFS was longer in observation group (7.53 months) than that in control group (4.57 months) $(p=0.0033)$. In Cox regression analysis, the Eastern Cooperative Oncology Group performance status score, brain metastases and metastatic sites were prognostic factors of ICls plus anlotinib. Compared with control group, Grade 3-4 adverse events did not increase significantly in observation group. Treatment-related adverse events were tolerable and controllable.

Conclusion: ICls plus anlotinib showed promising efficacy and low toxicity in third-line treatment of ESSCLC.

\section{Introduction}

As is shown in 2020 Global cancer statistics, the number of new cases and deaths of lung cancer are 2.2 million and 1.8 million, respectively. The incidence rate is second only to breast cancer and colorectal cancer, and the mortality rate is second only to breast cancer(Siegel, et al. 2020). SCLC accounted for 13 $\%$ to17\%, and smoking was the main cause of SCLC(Oronsky, et al. 2017;Govindan, et al. 2006). SCLC has the characteristics of high degree of malignancy and early metastasis. Therefore, a large number of people are already at an extensive stage at the time of diagnosis(Kalemkerian 2016;Simon and Wagner 2003).

Tumor proliferation, migration and reproduction depend on the formation of tumor new blood vessels. Because tumor cells stimulate angiogenesis and transport oxygen while producing too many factors that promote blood vessel growth, tumor new blood vessels are immature(Carmeliet and Jain 2011). Anlotinib, as a new oral small molecule multi-target tyrosine kinase inhibitor, mainly targets VEGFR, PDGFR, FGFR, c-Kit and other kinases so as to achieve anti-angiogenesis and anti-tumor effects. Professor (Cheng, et al. 2021). initiated a randomized, double-blinded, randomized, multi-center phase 2 trial of anlotinib versus placebo data for third-line and above SCLC. The ORR of the anlotinib group was $4.9 \%$, and the placebo 
group was $2.6 \%$. The DCR of the anlotinib group (71.6\%) was significantly higher than that of the placebo group $(13.2 \%, p<0.0001)$. Compared with the control group, the PFS of the anlotinib group was prolonged by 3.4 months ( 4.1 vs. 0.7 months), the overall survival (OS) was prolonged by 2.4 months (7.3 vs. 4.9 months), and the HR was 0.53. Therefore, the National Medical Products Administration approved anlotinib with the indication for third-line and above treatment of SCLC in September 2019.

The rise of immunotherapy provides more options for the treatment of ES-SCLC. The most commonly used ICls are programmed death receptor 1 (PD-1) and programmed death ligand 1 (PD-L1) inhibitors. PD-1/PD-L1 inhibitors mainly block the binding of PD-L1, which is highly expressed on tumor cells, to the receptor PD-1 on T cells. On the one hand, it can restore the activity of T cells, and on the other hand, effector T cells and Memory $T$ cells differentiate normally to enhance the immune effect of $T$ cells, thereby killing tumors (Efremova, et al. 2018). The results of the IMPOWER 133 study showed that atezolizumab plus platinum-containing dual-agent chemotherapy can prolong the median OS by 2 months (12.3 vs 10.3 months, $p=0.0154$ ) and the median PFS by 1 month ( 5.2 vs 4.3 months), the risk of disease progression can be reduced by $23 \%$ (Horn, et al. 2018; Liu, et al. 2019). In CASPIAN study, the median OS of durvalumab plus platinum-containing dual-agent was significantly better than the chemotherapy group (12.9 vs 10.5 months, $p=0.0047)$ and the incidence of adverse effects (AEs) in the two groups was similar (98.1\% vs $97 \%$ ) (Goldman, et al. 2021). Based on the results of IMPOWER133 study and CASPIAN study, atezolizumab and durvalumab were approved for the first-line treatment of ESSCLC. Atezolizumab and durvalumab can increase OS and reduce the risk of disease progression in the first-line treatment of ED-SCLC. In the second-line treatment of ES-SCLC, relevant studies have shown that the PD-1/PD-L1 inhibitor monotherapy failed to demonstrate significant efficacy (Spigel, et al. 2021;Pujol, et al. 2019). The results of the KEYNOTE028/158 study showed that the ORR of pembrolizumab for thirdline and above treatment of SCLC was $19.3 \%$, the PFS was 2.0 months $(95 \% \mathrm{Cl} 1.9-3.4$ months), and the median OS was 7.7 months ( $95 \% \mathrm{Cl}$ 5.2-10.1months) (Chung, et al. 2020). Based on this result, the Food and Drug Administration (FDA) approved pembrolizumab monotherapy for the treatment of patients with metastatic SCLC who had previously received platinum-containing chemotherapy and at least one other therapy. In the CheckMate-032 study, the subgroup analysis of the third-line treatment of nivolumab monotherapy showed the ORR was $19 \%$, the median PFS was 1.4 months ( $95 \% \mathrm{Cl} 1.3-1.6$ months) and the OS was 5.6 months ( $95 \% \mathrm{Cl} 3.1-6.8$ months) (Ready, et al. 2019). Based on this, FDA approved nivolumab alone for patients with metastatic SCLC who had previously received platinum-based chemotherapy and at least one other therapy.

More and more studies have shown that anlotinib and ICls complement each other and play a synergistic role in anti-tumor therapy. On the one hand, abnormal tumor neovascularization can block the accumulation and infiltration of surrounding $T$ cells into tumor tissues. Anlotinib can normalize tumor blood vessels and improve the immune microenvironment of the tumor. On the other hand, Allen et al. found that the decrease of PD-L1 expressed by endothelial cells can cause the increase of VEGFR-2, indicating that PD-L1 has a potential regulatory effect on tumor angiogenesis (Jiang, et al. 2015;Allen, et al. 2017;Ramjiawan, et al. 2017). 
Here, we evaluated the efficacy and safety of ICls plus anlotinib versus anlotinib alone in order to find a high-efficiency and low-toxic third-line treatment of ES-SCLC.

\section{Patients}

We reviewed the electronic medical records of 120 patients with advanced SCLC who received anlotinib alone $(n=58)$ or ICls plus anlotinib $(n=62)$ for the third-line treatment from January 2019 to November 2020 at Shandong Cancer Hospital, China. Inclusion criteria were as follows: (i) age at diagnosis between 18 and 75 years, (ii) the presence of pathologically or cytologically confirmed ES-SCLC, (iii) a prior lack of response or intolerance to two lines of treatment, (iv) the presence of at least one measurable lesion as defined by the Response Evaluation Criteria in Solid Tumors (RECIST) version 1.1, (v) an Eastern Cooperative Oncology Group performance status (ECOG PS) of $0-2$, and (vi) no prior anlotinib or ICls. Patients with non-small cell lung cancer, uncontrolled hypertension, a bleeding tendency or ischemic cardiovascular disease, severe liver and kidney dysfunction were excluded from the study. 58 patients received anlotinib alone. Anlotinib (Chia Tai Tianqing Pharmaceutical, China) was administered orally, once daily ( $8 \mathrm{mg}, 10 \mathrm{mg}$ or $12 \mathrm{mg}$ ) on days $1-14$ of a 21-day cycle. 62 patients received ICls plus anlotinib. anlotinib (Chia Tai Tianqing Pharmaceutical, China) was administered orally, once daily (8 mg, $10 \mathrm{mg}$ or $12 \mathrm{mg}$ ) on days 1-14 of a 21-day cycle. At the same time, the patients were treated with ICls. ICls included sintilimab, toripalimab, camrelizumab, atezolizumab, nivolumab and durvalumab (Table 1). Tolerance and treatment efficacy were evaluated every 2 cycles. The treatment was continued until disease progression, clinical deterioration, or unacceptable toxicity.

\section{Evaluation of Efficacy and Adverse Events}

According to the Response Evaluation Criteria in Solid Tumors (RECIST) version 1.1, ORR was defined as the sum of complete response (CR) and partial response (PR). DCR was defined as the sum of CR, PR and stable disease (SD). PFS was calculated as the time from the initiation of treatment to progressive disease (PD) or death. OS referred to the duration from the first treatment to death or the last follow-up. AEs were divided into grades I-IV according to the Common Terminology Criteria for Adverse Events (CTCAE) version 5.0; The higher the grade, the worse the AEs.

\section{Statistical analysis}

SPSS version 19.0 (IBM Corp., Armonk, NY, USA) was used for all statistical analyses. The median PFS was calculated using the Kaplan-Meier method and the survival curves were compared by a log-rank test. Cox proportional hazards regression models were used to analyze the effect of baseline clinical characteristics on the efficacy of ICls plus anlotinib and estimate hazard ratios (HRs). A value of $p<0.05$ was considered statistically significant.

\section{Results}

\section{Patient characteristics}


A total of 120 patients who met the inclusion criteria were included in the study. Of observation group, 38 (61.3\%) were males and 24 (38.7\%) were females. Of control group, 43 (74.1\%) were males and 15 $(25.9 \%)$ were females. All of them aged 18 to 75 . There were no significantly differences in gender, age, smoking history, drinking history, ECOG PS, brain metastasis, liver metastasis, and metastatic sites of two groups $(p>0.05)$ (Table 2$)$.

\section{Efficacy}

The ORR of observation group was higher than that of control group ( $19.4 \%$ vs $6.9 \%, p=0.045)$; The DCR of observation group and control group were $87.1 \%$ and $72.4 \%$, respectively. The difference was statistically significant $(p=0.044)$ (Table 3$)$.

All patients received at least 2 cycles of treatment and follow-up. The deadline for follow-up was July 1 , 2021. The median PFS of observation group was 7.53 months ( $95 \% \mathrm{Cl}: 5.46-9.60$ months), and control group was 4.57 months ( $95 \% \mathrm{Cl}: 2.96-6.18$ months). There are differences between the two statistically significant ( $p=0.0033$ ) (Fig. 1). We used Cox regression model to analyze the PFS of age, gender, smoking history, drinking history, ECOG PS, liver metastases, brain metastases and metastatic sites on the effect of ICls plus anlotinib. Gender, age, smoking history, drinking history and liver metastases have no influence on PFS of the ICls plus anlotinib. ECOG PS, brain metastases and metastatic sites were factors affecting the efficacy of ICls plus anlotinib (Table 3 ). Among all patients of observation group, the median PFS of patients without brain metastases was 7.53 months, and the median PFS of patients with brain metastases was 4.57 months. The difference was statistically significant ( $p=0.0062$ ) (Fig. 2 ). Patients with ECOG PS of $0-1$ have a significantly higher median PFS than patients with ECOG PS of 2 (8.23 vs. 4.63 months, $p=0.0056$ ) (Fig. 3). Patients with less than or equal to three metastatic sites have a higher PFS than those with more than three metastatic sites (10.6 vs 4.0 months, $p=0.0054$ ) (Fig. 4 ).

\section{Safety}

Compared with the control group, the grade 1-2 AEs including immune-related pneumonia $(p=0.008)$ and hypothyroidism $(p=0.002)$ significantly increased in the observation group. There was no significant difference in the incidence of grade 3-4 AEs. In observation group, no patients discontinued the use of drugs and 6 patients reduced the dose of anlotinib due to hypertension, bone marrow suppression and hand-foot syndrome; 2 patients discontinued the use of drugs and 10 patients reduced the dosed of anlotinib in observation group due to hypertension, bone marrow suppression, hand-foot syndrome and immune-related pneumonia. Generally speaking, the AEs in the observation group were still tolerable (Table 4, Table 5).

\section{Discussion}

In this study, we evaluated the efficacy and safety of ICls plus anlotinib versus anlotinib alone in 120 patients with ES-SCLC. We divided these patients into observation group $(n=62)$ and control group $(n=$ 58). Patients in observation group received ICls plus anlotinib, and patients in control group received 
anlotinib alone. In observation group, 2 patients had CR (3.2\%), 10 patients had PR (16.1\%), 43 patients had SD (67.8\%), and 8 patients had PD (12.9\%). In control group, no patients had CR $(0.0 \%), 4$ patients had PR (6.9\%), 38 patients had SD (65.5\%), and 16 patients had PD (27.6\%). DCR in observation group $(87.1 \%)$ was higher than that in control group $(72.4 \%, p=0.044)$, and ORR in observation group and control group were $19.4 \%$ and $6.9 \%(p=0.045)$, respectively. The PFS of observation group was 7.53 months (95\% Cl: $5.46-9.60$ months) and that of control group was 4.57 months (95\% Cl: $2.96-6.18$ months, $p=0.033$ ). Univariate and multivariate analysis showed that metastatic sites, ECOG PS and brain metastases were related to PFS of ICls plus anlotinib. While age, gender, smoking history, drinking history and liver metastases were not directly related to prognosis. As mentioned above, the ORR, DCR and median PFS of patients treated with ICls plus anlotinib were higher than those of patients treated with anlotinib alone, and the addition of ICls did not significantly increase the grade 3-4 AEs of the patients. It is clear that the application of ICls plus anlotinib does benefit patients more than anlotinib alone. Consequently, the results of this study can also provide a reference for clinical workers.

The incidence of brain metastases from lung cancer is the highest of all tumors, and more than $25 \%$ patients develop brain metastases during the course of the disease (Zimm, et al. 1981 ;Sheehan, et al. 2002). Patients with brain metastases have a short survival period and poor performance status (Langer and Mehta 2005). In established brain metastases, the tumor microenvironment is composed of the innate immune system, namely microglia and macrophages, and adaptation to the immune system is mainly achieved through T cells. On the one hand, brain metastases can manipulate the metabolites and matrix components in their microenvironment to influence the immune response. On the other hand, brain metastases can regulate and activate the function of microglia and produce inducible nitric oxide synthase and tumor necrosis factor-a, which can lyse target cells (Holmgaard, et al. 2015;Munn and Mellor 2016; He, et al. 2006). Therefore, there are prerequisites for the response to immunotherapy in the microenvironment of brain metastases. In addition, anlotinib also has an effect on brain metastases. The ALTER 1202 subgroup analysis showed that the PFS of patients with brain metastases was prolonged by 3 months (3.8 vs 0.8 months, HR 0.15), and OS singing for 3.7 months (6.3 vs 2.6 months, HR 0.23 ) (Cheng, et al. 2019). In our study, the result of Cox regression analysis showed that brain metastasis is one of the factors that affect the efficacy of ICls plus anlotinib. Compared with the median PFS of the patients received anlotinib alone, the median PFS of patients received ICls plus anlotinib was prolonged by 2.96 months ( 7.53 vs 4.57 months, $p=0.0062$ ), which was considered to be one of the factors affecting the prognosis in COX regression. As a result, when receiving ICls plus anlotinib, ES-SCLC patients without brain metastases benefit more than patients with brain metastases.

As is shown in our study, the ECOG performance status was also an important independent prognostic factor in this study. The results showed that when the ECOG performance status was $0-1$, the median PFS of patients was 8.23 months, which was much longer than that of patients with the ECOG performance status 2 (4.63 months) $(p=0.0056)$. A meta-analysis of SCLC at different stages showed that ECOG PS is one of the important factors affecting the survival of ED-SCLC patients. Patients with a PS score of $0-1$ have the best prognosis, and patients with a PS score of $\geq 2$ have the worst prognosis (Foster, et al. 2009). The higher the ECOG performance status, the shorter the survival period (Reck, et al. 
2012). The patient with low ECOG PS means he can tolerate the treatment well. The lower the ECOG performance status, the better the effect of ICls plus anlotinib. Therefore, when the physical condition is good and the ECOG PS score is low, we recommend ICls plus anlotinib as the third-line treatment of EDSCLC.

In addition, the number of metastatic sites is also one of the non-negligible factors that affect the efficacy of ICls plus anlotinib. In our study, the median PFS of patients with less than three metastases was higher than that of patients with more than three metastases ( 10.6 vs 4.0 months, $p=0.0054$ ). This result suggests us that the less the number of metastatic sites, the better the efficacy of ICls plus anlotinib.

\section{Conclusion}

ICls plus anlotinib as third-line treatment of ES-SCLC can significantly benefit patients in ORR, DCR and PFS. Compared with anlotinib alone, the incidence of grade 3-4 AEs of ICls plus anlotinib is not significantly increased. The main AEs of ICls plus anlotinib are hypertension, hand-foot syndrome, hypothyroidism, and immune-related pneumonia. This study may provide new ideas for clinical antitumor therapy, and it is the hope that more patients can benefit from this therapeutic regimen. However, our study also has shortcomings. The sample size of our statistics is small, and there is no median OS result. We will continue to expand the sample size in our future studies to validate our results and obtain relevant data on the median OS of ICls plus anlotinib.

\section{Declarations}

\section{Acknowledgements}

The authors would like to thank for the support of the grant from the Shandong Key Research and Development Program (Grant number:2019GSF108251)

Funding This study was supported by the grant from the Shandong Key Research and Development Program (Grant number:2019GSF108251)

Code availability Not applicable

\section{Author contributions}

All authors contributed to the study conception and design. Material preparation, data collection and analysis were performed by QC, YL, SJL, WJZ. CW. The first draft of the manuscript was written by QC and all authors commented on the manuscript. All authors read and approved the final manuscript

Data availability Datasets generated and analyzed during the study are available from Q Chen on reasonable request.

Conflict of interest The authors declare that they have no conflict of interest. 
Ethical approval This study was conducted in accordance with the Declaration of Helsinki and approved by the Ethics Committee of the Cancer Hospital affiliated to Shandong First Medical University. The requirement for informed consent was waived due to the retrospective nature of the study.

Consent to participate Not applicable

\section{References}

1. Siegel RL, Miller KD, Jemal A (2020)Cancer statistics, 2020. CA Cancer J Clin;70:7-30. https://10.3322/caac. 21590

2. Oronsky B, Reid TR, Oronsky A, Carter CA (2017)What's new in SCLC? A review. Neoplasia;19:842847. https://10.1016/j.neo.2017.07.007

3. Govindan R, Page N, Morgensztern D, Read W, Tierney R, Vlahiotis A, Spitznagel EL, Piccirillo J (2006)Changing epidemiology of small-cell lung cancer in the United States over the last 30 years: analysis of the surveillance, epidemiologic, and end results database. J Clin Oncol;24:4539-4544. https://10.1200/JC0.2005.04.4859

4. Kalemkerian GP (2016)Small cell lung cancer. Semin Respir Crit Care Med;37:783-796. https://10.1055/s-0036-1592116

5. Simon GR, Wagner H (2003)Small cell lung cancer. Chest;123:259S-271S. https://10.1378/chest.123.1_suppl.259s

6. Carmeliet P, Jain RK (2011)Principles and mechanisms of vessel normalization for cancer and other angiogenic diseases. Nat Rev Drug Discov;10:417-427. https://10.1038/nrd3455

7. Cheng Y, Wang Q, Li K, Shi J, Liu Y, Wu L, Han B, Chen G, He J, Wang J, Lou D, Yu H, Wang S, Qin H, Li $X$ (2021)Anlotinib vs placebo as third- or further-line treatment for patients with small cell lung cancer: a randomised, double-blind, placebo-controlled phase 2 study. $\mathrm{Br} \mathrm{J}$ Cancerhttps://10.1038/s41416-021-01356-3

8. Efremova M, Rieder D, Klepsch V, Charoentong P, Finotello F, Hackl H, Hermann-Kleiter N, Lower M, Baier G, Krogsdam A, Trajanoski Z (2018)Targeting immune checkpoints potentiates immunoediting and changes the dynamics of tumor evolution. Nat Commun;9:32. https://10.1038/s41467-01702424-0

9. Horn L, Mansfield AS, Szczesna A, Havel L, Krzakowski M, Hochmair MJ, Huemer F, Losonczy G, Johnson ML, Nishio M, Reck M, Mok T, Lam S, Shames DS, Liu J, Ding B, Lopez-Chavez A, Kabbinavar F, Lin W, Sandler A, Liu SV, Group IMS (2018)First-line atezolizumab plus chemotherapy in extensive-stage small-cell lung cancer. N Engl J Med;379:2220-2229.

https://10.1056/NEJMoa1809064

10. Liu tV, Reck M, Reinmuth N, Orlandi F, Lam S, Mansfield AS, Deng Y, Mok T, Garassino MC, Nishio M, Carpeno JDC, Alatorre-Alexander J, McCleland M, Leal T, Scherpereel A, Califano R, Cheng Y, Phan S, Lee J-S, Horn L (2019)Updated overall survival and PD-L1 subgroup analysis of patients with 
extensive-stage small-cell lung cancer treated with atezolizumab, carboplatin, and etoposide (IMpower133). J Clin Oncol 37:537-546. https://10.1200/JC0.20

11. Goldman JW, Dvorkin M, Chen Yb, Reinmuth N, Hotta K, Trukhin D, Statsenko G, Hochmair MJ, Özgüroğlu M, Ji JH, assino MC, Voitko GO, Poltoratskiy A, Ponce S, Verderame F, Havel L, Bondarenko I, Każarnowicz A, Losonczy G, Conev NV, Armstrong J, Byrne N, Thiyagarajah P, Jiang Hy, Paz-Ares L (2021)Durvalumab, with or without tremelimumab, plus platinum-etoposide versus platinumetoposide alone in first-line treatment of extensive-stage small-cell lung cancer (CASPIAN): updated results from a randomised, controlled, open-label, phase 3 trial. Lancet Oncol;22:51-65. https://10.1016/S1470-2045(20)30539-8

12. Spigel DR, Vicente D, Ciuleanu TE, Gettinger S, Peters S, Horn L, Audigier-Valette C, Pardo Aranda N, Juan-Vidal O, Cheng Y, Zhang H, Shi M, Luft A, Wolf J, Antonia S, Nakagawa K, Fairchild J, Baudelet C, Pandya D, Doshi P, Chang H, Reck M (2021)Second-line nivolumab in relapsed small-cell lung cancer: CheckMate 3310. Ann Oncol;32:631-641. https://10.1016/j.annonc.2021.01.071

13. Pujol J-L, Greillier L, Audigier-Valette C, Moro-Sibilot D, Uwer L, Hureaux J, Guisier F, Carmier D, Madelaine J, Otto J, Gounant V, Merle P, Mourlanette P, Molinier O, Renault A, Rabeau A, Antoine M, Denis MG, Bommart S, Langlais A, Morin F, Souquet P-J (2019)A randomized non-comparative phase II study of anti-programmed cell death-ligand 1 atezolizumab or chemotherapy as second-line therapy in patients with small cell lung cancer: Results from the IFCT-1603 trial. Journal of Thoracic Oncology;14:903-913. https://10.1016/j.jtho.2019.01.008

14. Chung HC, Piha-Paul SA, Lopez-Martin J, Schellens JHM, Kao S, Miller WH, Jr., Delord JP, Gao B, Planchard D, Gottfried M, Zer A, Jalal SI, Penel N, Mehnert JM, Matos I, Bennouna J, Kim DW, Xu L, Krishnan S, Norwood K, Ott PA (2020)Pembrolizumab after two or more lines of previous therapy in patients with recurrent or metastatic SCLC: results from the KEYNOTE-028 and KEYNOTE-158 studies. J Thorac Oncol;15:618-627. https://10.1016/j.jtho.2019.12.109

15. Ready N, Farago AF, de Braud F, Atmaca A, Hellmann MD, Schneider JG, Spigel DR, Moreno V, Chau I, Hann CL, Eder JP, Steele NL, Pieters A, Fairchild J, Antonia SJ (2019)Third-line nivolumab monotherapy in recurrent SCLC: CheckMate 032. J Thorac Oncol;14:237-244. https://10.1016/j.jtho.2018.10.003

16. Jiang W, Huang Y, An Y, Kim BYS (2015)Remodeling tumor vasculature to enhance delivery of intermediate-sized nanoparticles. ACS Nano Actions Search in PubMed Search in NLM Catalog Add to Search 9:8689-8696. https://10.1021/acsnano.5b02028. Epub 2015 Jul 31

17. Allen E, Jabouille A, Rivera LB, Lodewijckx I, Missiaen R, Steri V, Feyen K, Tawney a, Hanahan D, Michael IP, Bergers G (2017)Combined antiangiogenic and anti-PD-L1 therapy stimulates tumor immunity through HEV formation. Sci Transl Med;9:1-13.

18. Ramjiawan RR, Griffioen AW, Duda DG (2017)Anti-angiogenesis for cancer revisited: is there a role for combinations with immunotherapy? Angiogenesis;20:185-204. https://10.1007/s10456-017-9552-y

19. Zimm S, Wampler GL, Stablein D, Hazra T, Young HF (1981)In tracerebrai metastases in solid-tumor patients: natural history and results of treatment. Cancer;48:384-394. https://10.1002/1097- 
0142(19810715)48:2<384::aid-cncr2820480227>3.0.co;2-8.

20. Sheehan J, Sun M, Kondziolka D, Flickinger J, Lunsford L (2002)Radiosurgery for non-small cell lung carcinoma metastatic to the brain: long-term outcomes and prognostic factors influencing patient survival time and local tumor control. J Neurosurg;97:1276-1281. https://10.3171/jns.2002.97.6.1276.

21. Langer CJ, Mehta MP (2005)Current management of brain metastases, with a focus on systemic options. J Clin Oncol;23:6207-6219. https://10.1200/JC0.2005.03.145

22. Holmgaard RB, Zamarin D, Li Y, Gasmi B, Munn DH, Allison JP, Merghoub T, Wolchok JD (2015)Tumor-expressed IDO recruits and activates MDSCs in a Treg-dependent manner. Cell Rep;13:412-424. https://10.1016/j.celrep.2015.08.077

23. Munn DH, Mellor AL (2016)IDO in the tumor microenvironment: Inflammation, counter-regulation, and tolerance. Trends Immunol;37:193-207. https://10.1016/j.it.2016.01.002

24. He BP, Wang JJ, Zhang X, Wu Y, Wang M, Bay BH, Chang AY (2006)Differential reactions of microglia to brain metastasis of lung cancer. Mol Med;12:161-170. https://10.2119/2006-00033.He

25. Cheng Y, Wang Q, Li K, Shi J, Han B, Wu L, Chen G, He J, Wang J, Qin H, Li X (2019)The impact of anlotinib for relapsed SCLC patients with brain metastases: a subgroup analysis of ALTER 1202. Journal of Thoracic Oncology;14:S823-S824. https://10.1016/j.jtho.2019.08.1771

26. Foster NR, Mandrekar SJ, Schild SE, Nelson GD, Rowland KM, Jr., Deming RL, Kozelsky TF, Marks RS, Jett JR, Adjei AA (2009)Prognostic factors differ by tumor stage for small cell lung cancer: a pooled analysis of North Central Cancer Treatment Group trials. Cancer;115:2721-2731. https://10.1002/cncr.24314

27. Reck M, Thatcher N, Smit EF, Lorigan P, Szutowicz-Zielinska E, Liepa AM, Winfree KB, Peterson P, Guba SC, Socinski MA (2012)Baseline quality of life and performance status as prognostic factors in patients with extensive-stage disease small cell lung cancer treated with pemetrexed plus carboplatin vs. etoposide plus carboplatin. Lung Cancer;78:276-281. https://10.1016/j.lungcan.2012.09.002

\section{Tables}

Table 1 Application of immune checkpoints

\begin{tabular}{ll} 
PD-1/PD-L1 inhibitor & Total \\
\hline Sintilimab & 18 \\
\hline Toripalimab & 4 \\
\hline Camrelizumab & 14 \\
\hline Atezolizumab & 12 \\
\hline Nivolumab & 4 \\
\hline Durvalumab & 11 \\
\multicolumn{1}{r}{ Page $11 / 17$} &
\end{tabular}


Table 2 Baseline Characteristics of Two Group

\begin{tabular}{|c|c|c|c|c|}
\hline Characteristics & Observation group & Control group & $x^{2}$ & $p$-value \\
\hline Age, n (\%) & & & 0.000 & 0.994 \\
\hline$<=65$ & $47(75.8 \%)$ & $44(75.9 \%)$ & & \\
\hline$>65$ & $15(24.2 \%)$ & $14(24.1 \%)$ & & \\
\hline Sex, n (\%) & & & 2.255 & 0.133 \\
\hline Male & $38(61.3 \%)$ & $43(74.1 \%)$ & & \\
\hline Female & $24(38.7 \%)$ & $15(25.9 \%)$ & & \\
\hline ECOG PS, n (\%) & & & 0.965 & 0.326 \\
\hline $0-1$ & $48(77.4 \%)$ & 49 (84.5\%) & & \\
\hline 2 & $14(22.6 \%)$ & $9(15.5 \%)$ & & \\
\hline Smoking history, n (\%) & & & 0.072 & 0.789 \\
\hline Yes & $25(40.3 \%)$ & $22(37.9 \%)$ & & \\
\hline No & $37(59.7 \%)$ & $36(62.1 \%)$ & & \\
\hline Drinking history, n (\%) & & & 1.877 & 0.171 \\
\hline Yes & $8(12.9 \%)$ & $13(22.4 \%)$ & & \\
\hline No & $54(87.1 \%)$ & $45(77.6 \%)$ & & \\
\hline Liver metastases, n (\%) & & & 0.044 & 0.833 \\
\hline Absent & $46(74.2 \%)$ & $44(75.9 \%)$ & & \\
\hline Present & $16(25.8 \%)$ & $14(24.1 \%)$ & & \\
\hline Brain metastases, $n(\%)$ & & & 0.109 & 0.741 \\
\hline Absent & $27(43.5 \%)$ & $27(46.6 \%)$ & & \\
\hline Present & $35(56.5 \%)$ & $31(53.4 \%)$ & & \\
\hline Metastatic sites, n (\%) & & & 0.058 & 0.810 \\
\hline$\leq 3$ & $35(56.5 \%)$ & $34(58.6 \%)$ & & \\
\hline$>3$ & $27(43.6 \%)$ & $24(41.4 \%)$ & & \\
\hline
\end{tabular}

ECOG PS. Eastern Cooperative Oncology Group Performance Status

Table 3 The short-term efficacy of the two groups of patients 


\begin{tabular}{|c|c|c|c|c|c|c|c|c|}
\hline Group & CR & PR & SD & PD & ORR & $p$-value & DCR & $p$-value \\
\hline Observation group & 2 & 10 & 42 & 8 & $12(19.4 \%)$ & \multirow[t]{2}{*}{0.045} & $54(87.1 \%)$ & \multirow[t]{2}{*}{0.044} \\
\hline Control group & 0 & 4 & 38 & 16 & $4(6.9 \%)$ & & $42(72.4 \%)$ & \\
\hline
\end{tabular}

Table 4 Univariate and multivariate cox regression analysis of factors associated with PFS

\begin{tabular}{lllll} 
Characteristics & \multicolumn{3}{l}{ Univariate analysis } & \multicolumn{2}{l}{ Multivariate analysis } \\
\cline { 2 - 5 } & HR 95\% Cl & $p$-value & HR 95\% Cl & $p$-value \\
\hline Age ( $\leq 65$ vs $>65)$ & $0.827-5.036$ & 0.122 & $\mathrm{NI}$ \\
\hline Gender (Male vs Female) & $0.638-2.583$ & 0.483 & $\mathrm{NI}$ \\
\hline Smoking history (Yes vs No) & $0.374-1.531$ & 0.437 & $\mathrm{NI}$ \\
\hline Drinking history (Yes vs No) & $0.262-1.549$ & 0.320 & & $\mathrm{NI}$ \\
\hline ECOG PS (0-1 vs 2) & $0.185-0.777$ & 0.080 & $0.197-0.871$ & $\mathbf{0 . 0 0 4}$ \\
\hline Liver metastases (Yes vs No) & $0.410-1.625$ & 0.563 & & $\mathrm{Nl}$ \\
\hline Brain metastases (Yes vs No) & $0.178-0.778$ & $\mathbf{0 . 0 0 9}$ & $0.187-0.903$ & $\mathbf{0 . 0 2 7}$ \\
\hline Metastatic sites ( $\leq 3$ vs >3) & $0.196-0.781$ & $\mathbf{0 . 0 0 8}$ & $0.172-0.712$ & $\mathbf{0 . 0 0 2}$
\end{tabular}

ECOG PSEastern Cooperative Oncology Group Performance Status, $H R$ hazard ratio, $C /$ confidence interval, $N /$ not included in multivariate model, Boldness indicates $p$-value less than 0.05 .

Table 5 Treatment administration and dose modification of anlotinib

Dose of anlotinib

\begin{tabular}{lll}
\hline & Observation group & Control group \\
\hline Initial dosage, $\mathbf{~ m g ~}$ & & \\
\hline 8 & 8 & 6 \\
10 & 17 & 10 \\
12 & 37 & 42 \\
\hline Modification of dosage, $\mathbf{m g}$ & & \\
\hline $10 \rightarrow 8$ & 3 & 2 \\
\hline $12 \rightarrow 10$ & 6 & 3 \\
$12 \rightarrow 8$ & 1 & 1
\end{tabular}


Table 6 Treatment-related adverse events in the two groups[n\%]

\begin{tabular}{|c|c|c|c|c|c|c|}
\hline \multirow[t]{2}{*}{ AEs } & \multicolumn{2}{|c|}{ Grades 1-2 } & \multirow{2}{*}{$\begin{array}{l}p- \\
\text { value }\end{array}$} & \multicolumn{2}{|c|}{ Grades 3-4 } & \multirow{2}{*}{$\begin{array}{l}p- \\
\text { value }\end{array}$} \\
\hline & $\begin{array}{l}\text { Control } \\
\text { group }\end{array}$ & $\begin{array}{l}\text { Observation } \\
\text { group }\end{array}$ & & $\begin{array}{l}\text { Control } \\
\text { group }\end{array}$ & $\begin{array}{l}\text { Observation } \\
\text { group }\end{array}$ & \\
\hline Hypertension & $\begin{array}{l}10 \\
(17.2 \%)\end{array}$ & $12(19.3 \%)$ & 0.765 & $4(6.9 \%)$ & $5(8.1 \%)$ & 0.808 \\
\hline $\begin{array}{l}\text { Bone marrow } \\
\text { suppression }\end{array}$ & $5(8.6 \%)$ & $9(14.5 \%)$ & 0.315 & $0(0.0 \%)$ & $2(3.2 \%)$ & 0.168 \\
\hline Transaminitis & $0(0.0 \%)$ & $2(3.2 \%)$ & 0.168 & $0(0.0 \%)$ & $0(0.0 \%)$ & - \\
\hline Fatigue & $3(5.2 \%)$ & $7(11.3 \%)$ & 0.226 & $0(0.0 \%)$ & $0(0.0 \%)$ & - \\
\hline Rash & $0(0.0 \%)$ & $3(4.8 \%)$ & 0.090 & $0(0.0 \%)$ & $0(0.0 \%)$ & - \\
\hline Vomiting/Diarrhea & $5(8.6 \%)$ & $6(9.7 \%)$ & 0.841 & $0(0.0 \%)$ & $2(3.2 \%)$ & 0.168 \\
\hline Cough & $2(3.4 \%)$ & $1(1.6 \%)$ & 0.520 & $0(0.0 \%)$ & $0(0.0 \%)$ & - \\
\hline Hand-foot syndrome & $8(13.8 \%)$ & $11(17.7 \%)$ & 0.554 & $3(5.2 \%)$ & $5(8.1 \%)$ & 0.526 \\
\hline Gingival bleeding & $5(8.6 \%)$ & $6(9.7 \%)$ & 0.841 & $0(0.0 \%)$ & $1(1.6 \%)$ & 0.331 \\
\hline $\begin{array}{l}\text { Gastrointestinal } \\
\text { bleeding }\end{array}$ & $2(3.4 \%)$ & $3(4.8 \%)$ & 0.703 & $0(0.0 \%)$ & $1(1.6 \%)$ & 0.331 \\
\hline Hypothyroidism & $0(0.0 \%)$ & $11(17.7 \%)$ & 0.002 & $0(0.0 \%)$ & $2(3.2 \%)$ & 0.168 \\
\hline $\begin{array}{l}\text { Immune-related } \\
\text { pneumonia }\end{array}$ & $0(0.0 \%)$ & $7(11.3 \%)$ & 0.008 & $0(0.0 \%)$ & $3(4.8 \%)$ & 0.090 \\
\hline
\end{tabular}

AEs adverse events, Boldness indicates $p$-value less than 0.05 .

\section{Figures}




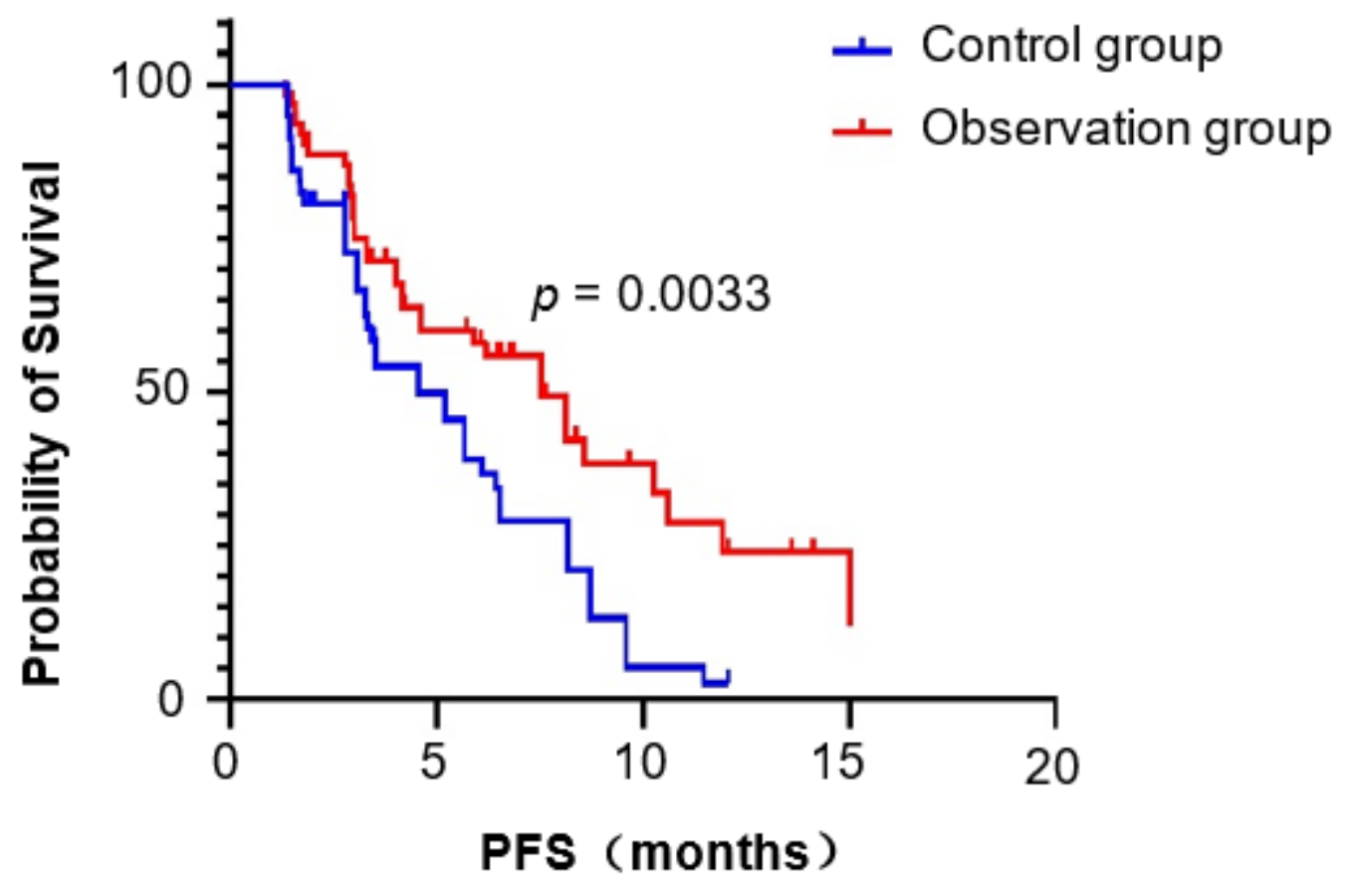

Figure 1

Kaplan-Meier survival curves of the progression-free survival (PFS) of two groups

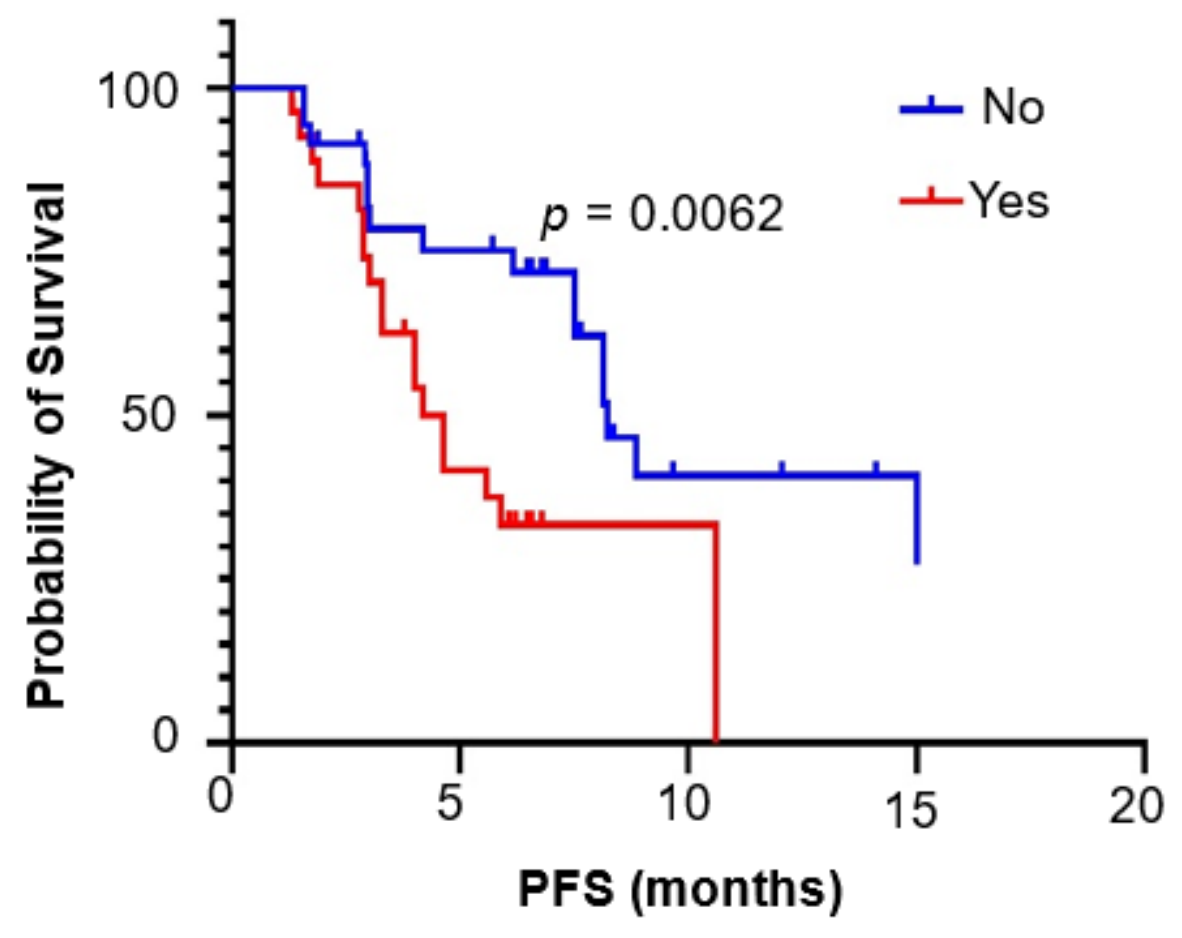

Figure 2

Kaplan-Meier survival curves for PFS were compared among observation group with or without brain metastases 


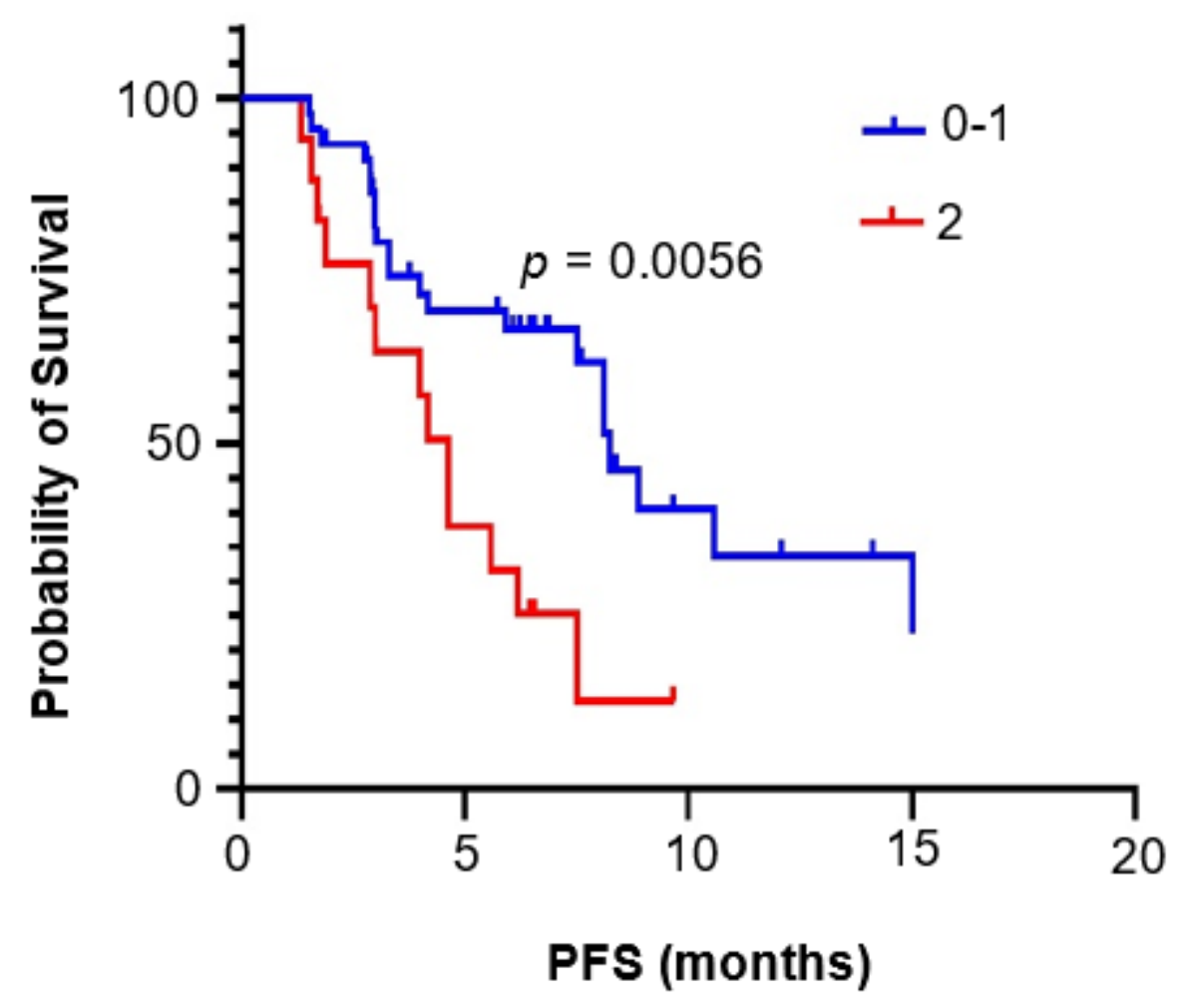

Figure 3

Kaplan-Meier survival curves for PFS were compared among observation group with different Eastern Cooperative Oncology Group performance status ECOG PS Eastern Cooperative Oncology Group performance status 


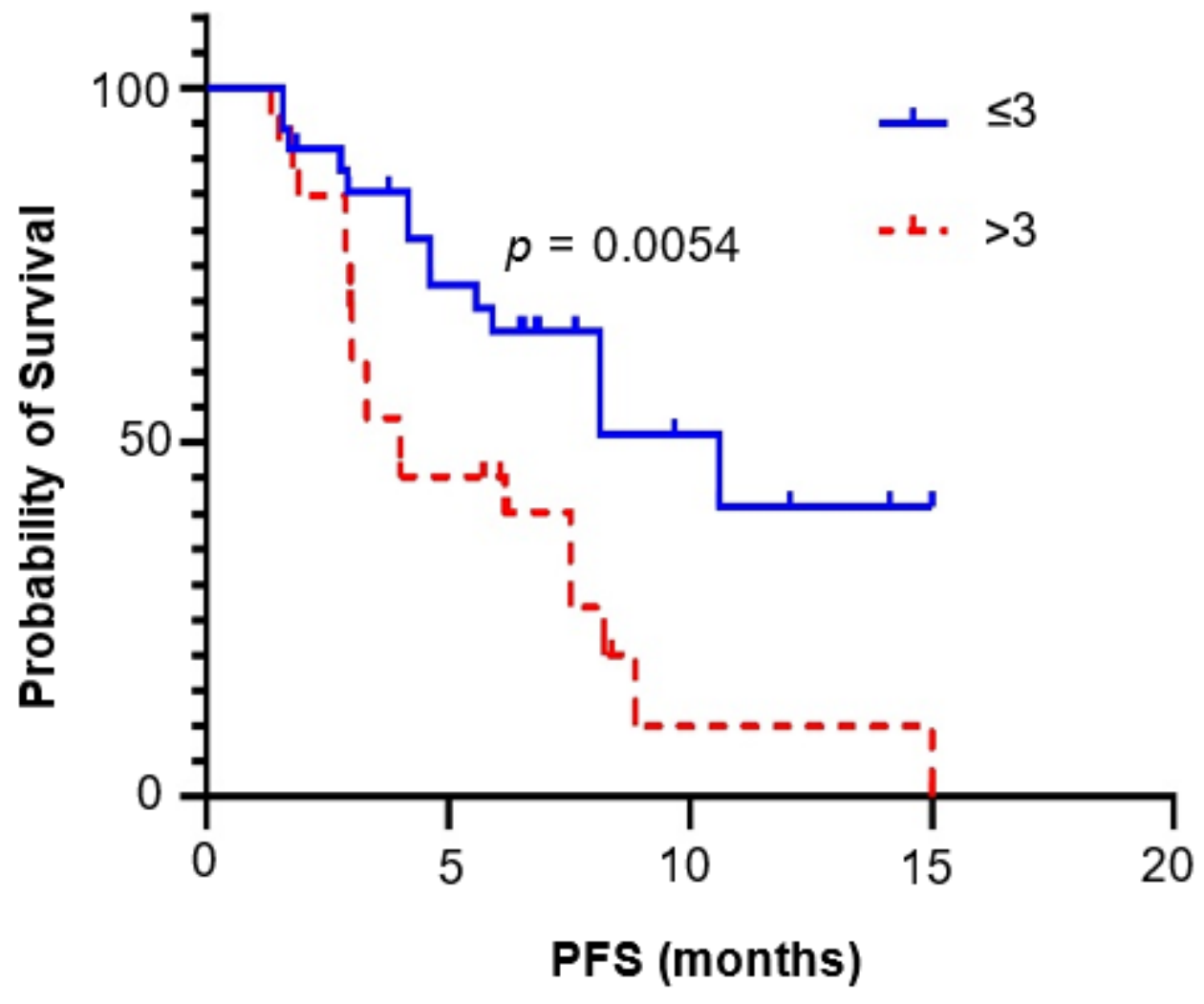

Figure 4

Kaplan-Meier survival curves for PFS were compared among observation group with different metastatic sites 